\title{
Ueber Catechu;
}

von

\section{H. Wackenroder.}

Das Catechu ist bekanntlich schon oft Gegenstand weitläuftiger Discussionen gewesen, ohne dals man zu übereinstimmenden Resultaten und Ansichten in dieser Beziehung gelangt wäre. Einer ausführlichen $\Delta$ rbeit über das Catechu, in welcher vornämlich die Catechusäure berücksichtigt zu werden verdient, dürften nachfolgende Notizen nützlich sein.

Ich unterscheide in Uebereinstimmung mit Martius und andern Pharmakognosten dreierlei Arten von Catechu, nämlich das Catechu von Bombay, das aus Bengalen und den Gambir oder Gambeer. Die erste Art wird als die ächte und wahre zu betrachten und als lediglich officinell anzusehen sein, wenn man den Catechugerbstoff für das vorzugsweise medicinisch Wirksame in dieser Drogue halten will.

1) Das Bombay - Catechu ist bekanntermaafsen eine dunkelbraune, gleichförmig gefärbte Extractmasse von einem verhältnifsmäl'sig grofsen specifischen Gewicht. Zuweilen erscheint dasselbe in einer unreinen Sorte, mehr und weniger gemischt mit Pflanzentheilen. Das Bombay-Catechu führt jetzt im Handel zuweilen den Namen Catechu in Kugeln. Sodann kommt auch, und wie mir scheint, erst in neuerer Zeit, ein sogenanntes Catechu verum vor, welches sich von dem älteren Catechu durch eine mehr braunrothe Farbe, starken Fettglanz, splitterig-muscheligen Bruch und Durchscheinheit an den Kanten unterscheidet. Sein chemisches Verhalten habe ich nicht untersucht. 
Das ältere Bombay - Catechu der reinsten Art, welches einen ganz unebenen Bruch zeigt, schwach fettartig glänzend und undurchsichtig ist, bildet in zerriebenem Zustande mit der achtfachen Menge kalten Wassers eine dunkelbraune, an Gerbstoff reiche Flüssigkeit. Sowohl Leim, als auch Schwefelsäure, bringen in dieser Auflösung starke Niederschläge hervor. Der von dem kalten Wasser zurüclggelassene, nicht bedeutende Antheil dieses Catechus wird von acht Theilen kochenden Wassers beinahe völlig aufgenommen zu einer stark dunkelbraunen, gerbsäurereichen Flüssigkeit, aus welcher sich auch bei langem Stehen verhältnifsmälsig nur wenig Catechusäure in Gestalt kleiner, warzenförmiger Häufchen absetzt. Die auf einem Filtrum mit kaltem Wásser ausgewaschene Säure erscheint nach dem Trocknen als eine bräunlichweifse, schimmernde, blättrige Masse, welche sich durch Digestion mit Kohle leicht reinigen läfst.

2) Das bengalische Catechu hat ein geringeres specifisches Gewicht, als das vorhergehende, und eine hellbraune bis gelbbraune Farbe. Auf dem Bruch ist es nur schimmernd und von feinen dunkelbraunen, glänzenden Streifen, welche nach der Au ¡senfläche der Stücke hin vorwalten, durchzogen, und ist undurchsichtig. Gegenwärtig trifft man auch im Handel auf ein sogenanntes Catechu ostindicum, welches jenem älteren Catechu verwandt zu sein scheint. Dasselbe ist braungelb, wachsartig glänzend auf dem Bruch, und an den Kanten mit rothbrauner Farbe durchscheinend. Sein chemisches Verhalten ist mir unbekannt.

Das ältere, im Innern feinstreifige bengalische Catechu bildet mit kaltem Wasser eine weniger gefärbte und weniger gerbstoffhaltige Flüssigkeit, als das Catechn von Bombay. Der hinterbleibende bedeutende Rückstand 
von bräunlich - grauer Farbe löst sich dagegen beim Kochen mit acht Theilen Wasser zum Theil, und bei erneuertem Kochen mit eben so viel Wasser grörstentheils auf. Aus den Abkochungen scheidet sich beim Stehen eine grofse Menge fast ganz reiner Catechusäure $a b$, über deren sehr einfache vollständige Reinigung und interessante Eigenschaften in einem der nächsten Stücke der Annalen der Pharmacie einige Notizen von mir werden mitgetheilt werden.

3) Als eine besondere Art des Catechus ist der Gambir (oder Gambeer) zu betrachten. Es ist gewils eben so unrichtig, den Gambir für ein nachgelünsteltes, als für das beste Catechn anzusehen. Die cubischen Stücke des Gambirs sind bald 1 bis $1 \frac{1}{2}$ Zoll, bald nur $\frac{1}{2}$ Zoll dick. Aufser der Gröfse der Stücke scheint kein erheblicher Unterschied zwischen dem grofswürfeligen und kleinwürfeligen Gambir Statt zu finden. Der Bruch des Gambirs ist immer eben und matt, und nur zuweilen erscheint, namentlich der kleinwürfelige, unter der Lupe schimmernd von glänzenden Puncten. Mittelst des Mikroskops erkennt man immer nur eine hellbräunliche durchscheinende Masse in der Art krystallinisch, wie sich der Krümelzucker dem unbewaffneten Auge gewöhnlich darbietet. Die Farbe des Gambirs im Innern ist gleichförmig braungelb bis hellgelbbraun.

Der zerriebene Gambir wird von kaltem Wasser wenig, von kochendem Wasser beinahe vollständig aufgelöst. Die Auflösung ist dunkelbraunroth, schleimig und trübe. Sie wird durch Digestion mit gereinigter Knochenkohle völlig klar und durchsichtig, behält aber ihre braunrothe Farbe. Weder aus der trüben, noch aus der klaren Flüssigkeit scheidet sich jedoch beim Stehen Catechusäure ab. Geschieht die Digestion mit 
Knochenkohle nebst ganz wenig Salzsäure, so erfolgt zwar eine fast völlige Entfärbung der Flüssigkeit, aber doch keine Ausscheidung von Catechusäure. Wird die mit Thierkohle geklärte Flüssigkeit über Schwefelsäure unter dem Recipienten der Luftpumpe abgedampft, so hinterbleibt eine oberflächlich dunkelbraune, unterhalb weifse, leicht zerreibliche Masse ohne alle Spur einer Krystallisation. Läfst man dagegen einen Tropfen derselben auf einer Glastafel an der Luft eintrocknen, so bildet ein Theil derselben einen durchsichtigen Firnifs, während der andere Theil in feinen, aber stumpfen Nadeln krystallisirt. Auch wenn die nicht geklärte Auflösung an der Luft verweilt, setzen sich krystallinische Körner am Rande derselben in geringer Menge ab.

Die unklare Auflösung wird durch mehrmaliges Filtriren nicht klar. Durch Weingeist wird sie aber fast völlig geklärt, und nur wenige Flocken scheiden sich ab. Beim Verdünnen mit Wasser bleibt sie trübe, lklärt sich aber vollkommen, wenn zugleich etwas Weingeist hinzugefügt wird. Mit frischer Hausenblaselösung giebt sie einen zähen, braunrothen, und mit Schwefelsäure in gewöhnlicher Verdünnung einen starken, braungelben Niederschlag. Verdünntes Eisenchlorid bringt einen graugrünen Niederschlag darin hervor, welcher aber schwarz erscheint, wenn essigsaures Natron hinzugefügt worden. Eine frisch bereitete Auflösung des schwefelsauren Eisenoxyduls vermischt sich ohne alle Veränderung mit der Auflösung des Gambir. Erst beim Stehen an der Luft bildet sich allmälig ein graugrüner Niederschlag. Wird indessen sehr wenig Alkali, oder auch nur kalkhaltiges Brunnenwasser hinzugefügt, so entsteht augenblicklich ein blauschwarzer Niederschlag. Fin noch stärkerer blauschwarzer Niederschlag bildet 
sich sogleich, wenn dem ungefärbten Gemische essigsaures Natron hinzugesezt wird.

Diese schwarze Fällungen der Eisensalze durch den Gambir rühren aber nicht etwa her von Eichengerbsäure oder Gallussäure, sondern von der Catechusäure selbst, wie ich dieses in den oben erwähnten Notizen in den Annalen der Pharmacie genauer angegeben habe. Die Gerbsäure des Catechus scheint dasselbe Verhalten zu zeigen. Welche Umstände indessen die Ausscheidung der Catechusäure aus der Auflösung des Gambir fast ganz verhindern, das müssen erst weitere Versuche nachweisen.

\section{Notiz über Kampher und Epheuharz; vom} Professor Dr. Göppert in Breslau.

Im vergangenen Winter versuchte ich, bei Gelegenheit physiologischer Demonstrationen, Kampher mit dem in unsern Gewächshänsern kultivirten Laurus Camphora durch Destillation mit Wasser darzustellen und erhielt eine nicht unbedeutende Quantität des schönsten weifsen Kamphers. Da nun der rohe Kampher in sehr grauweifsen schmutzigen Körnern im Handel vorkömmt, so kann dieses nur Folge eines in hohem Grade rohen und unreinlichen Verfahrens sein *).

*) Hr. Professor Dr. Göppert hatte die Güte, mir etwas dieses Kamphers mitzutheilen, der sehr schön und weirs ist; ich erinnere hierbei an eine früher mitgetheilte Beobachtung, die mir vor zwölf Jahren bereits Nestler, bei meiner Anwesenheit in Strasburg, erzählte, der aus dem im dortigen botanischen Garten cultivirten Kampherbaum ebenfalls Kampher dargestellt hatte. 